\title{
专题：地球生物学前沿
}

论 文

\section{华南中二叠统栖霞组海相烃源岩形成的 地球生物学过程}

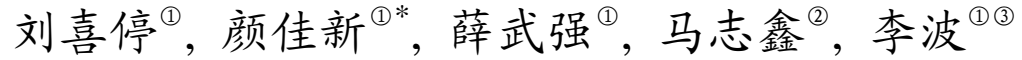 \\ (1) 生物地质与环境地质国家重点实验室, 中国地质大学地球科学学院, 武汉 430074; \\ (2) 成都地质矿产研究所, 成都 610081 ; \\ (3)广州海洋地质调查局, 广州 510760 \\ * 联系人, E-mail: jxyan@cug.edu.cn
}

收稿日期: 2013-04-27; 接受日期: 2013-09-02; 网络版发表日期: 2014-05-09

国家重点基础研究发展计划项目(编号: 2011CB808800)和国家自然科学基金项目(批准号: 41072078)资助

\begin{abstract}
摘要华南中二叠统栖霞组海相烃源岩是中国南方四套区域性烃源岩的重要组成部分, 对 其形成机制的研究具有重要的科学和经济意义. 前人的研究成果表明中二叠世栖霞期具有较 高的初级生产力和相对缺氧的环境, 但是对于高生产力和缺氧环境的形成机制一直存有争议. 本文利用地球生物学正演评价的思路, 整合研究程度相对较高的四川广元上寺剖面的研究成 果, 对华南栖霞组海相烃源岩的形成过程进行了阐述. 利用现实主义原理, 恢复了栖霞期的古 洋流格局, 认为较高的生产力是海平面上升诱发的赤道上升流的结果, 其营养元素来自沿赤道 自西向东的赤道潜流. 高生产力输出大量有机质而消耗水体中的可溶氧, 形成栖霞组独特的古 氧相特征. 在水体较深的生境型中, 有机质经过厌氧氧化作用而被保存, 成为栖霞组海相烃源 岩的物质基础. 地球生物学为研究栖霞组海相烃源岩的形成机制提供了新的思路.
\end{abstract}

关键词

栖霞组

烃源岩

生产力

古氧相

地球生物学

华南
中国古生界海相烃源岩具有高、过成熟和低有机 质丰度的特征, 对其评价一直是一个科学难题(陈建 平等, 2012; 腾格尔等, 2006). 近些年来, 地球生物 学方法的应用与实践为探索这一难题开辟了新的契 机(谢树成等, 2007). 地球生物学对海相烃源岩形成 过程的生物生产力, 沉积有机质和埋藏有机质三个 关键环节进行综合评价, 并且提出了地球生物相的 概念(殷鸿福等, 2008). 地球生物学方法已经运用到 不同地质历史时期的海相烃源岩的评价, 促进了对 中国南方海相烃源岩形成机制的认识(曹婷婷等,
2011; 陈慧等, 2010; 贾建忠等, 2009; 郄文昆等, 2007). 栖霞组是中国南方四套海相烃源岩的重要组 成部分, 其形成机制一直是研究的热点(刘峰等, 2011; 韦恒叶等, 2011). 本文结合前人的研究成果, 以四川 广元上寺剖面为例, 对该套烃源岩形成的地球生物 学过程进行了讨论.

\section{1 地质背景}

华南地区中二叠统栖霞组在区域上分布广泛,

中文引用格式: 刘喜停, 颜佳新, 薛武强, 等. 2014. 华南中二叠统栖霞组海相烃源岩形成的地球生物学过程. 中国科学: 地球科学, 44: 1185-1192

英文引用格式: Liu X T, Yan J X, Xue W Q, et al. 2014. The geobiological formation process of the marine source rocks in the Middle Permian Chihsia Formation of South China. Science China: Earth Sciences, 57: 957-964, doi: 10.1007/s11430-013-4737-8 
岩性和厚度稳定, 具有富含有机质和燧石结核的特 征(颜佳新, 2004). 栖霞期的华南是一个没有古陆存 在的, 盐度正常, 生物繁盛的统一的陆表海, 沉积了 独特的栖霞组灰岩(冯增昭和杨玉卿，1996). 华南栖 霞期主要发育浅水碳酸盐台地、深水陆棚和台内盆地 环境(图 1).

广元上寺剖面位于四川省广元市剑阁县上寺镇 北部的长江沟(图 1), 前人对该剖面栖霞组进行过大 量沉积学、地球化学、地层学和地球生物学的研究 (李 波等, 2012; 李朋威等, 2010; 马志金等, 2011). 栖霞 组厚约 $228 \mathrm{~m}$, 按岩性特征分为三段: 栖霞组下段为 深灰色中厚层的生物碎屑灰岩夹海泡石页岩, 生物 化石丰富, 见横板珊瑚、腕足和苔藓虫等, 为浅水碳 酸盐岩台地环境; 中段为灰白色巨厚层-块状似球粒 生屑灰岩, 见海百合茎、横板珊瑚和腕足等化石, 属 于较高能的滩相环境(马志金等, 2011). 上段为灰黑 色中厚层生物碎屑灰岩夹海泡石页岩, 构成灰岩-泥 灰岩韵律层, 是该地区海相烃源岩发育的重要层位, 主要为陆棚环境(刘喜停等, 2012).

\section{2 地球生物相特征}

\section{1 生产力}

由于栖霞期的海侵, 研究区受陆源输入影响较 小, 因此水体中沉降的颗粒物主要为生物碎屑, 而生 物碎屑的沉降通量则主要取决于表层海洋的初级生 产力(Franois 等, 1997), 所以本文选择薄片中单位面 积内生物碎屑的百分含量表征生产力的高低( $\mathrm{Ma}$ 等, 2008b). 古海洋初级生产力的评价还可以利用各种地 球化学指标, 包括营养元素的含量、有机碳通量及其 相关的微量元素的富集程度(胡超涌等, 2007). 虽然 生源钡和生源铝的形成过程尚有争议, 但它们的通 量与海洋生产力的变化存在很好的相关性却早已被 证实(Dymond 等, 1992; Murray 和 Leinen, 1996), 因此 过剩钡和过剩铝(沉积物中除去陆源那部分贡献后所 剩余的钡和铝)可以指示栖霞期研究区内生产力的高 低(Ma 等, 2008a; 殷鸿福等, 2011).

前人对广元上寺剖面栖霞组的初级生产力进行 了系统的研究, 结果表明栖霞组中部生产力水平较

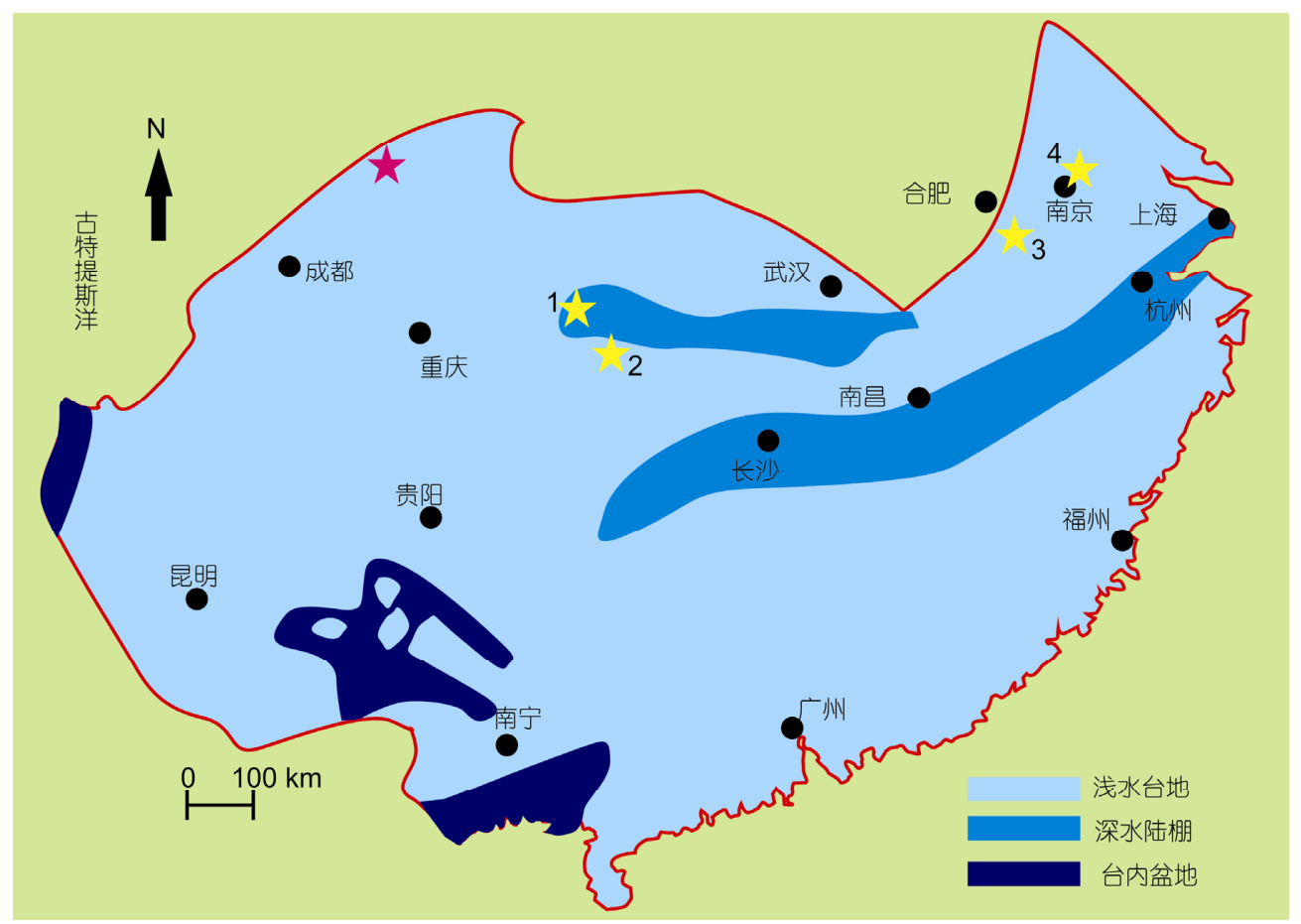

图 1 研究剖面位置和华南地区栖霞期岩相古地理

红色星号为四川广元上寺剖面, 黄色剖面为文中提到的剖面. 1 , 湖北恩施谭家坝村; 2 , 湖南桑植夹石河; 3 , 安徽巢湖茨苔山; 4 , 江苏南京栖 霞山. 据冯增昭和杨玉卿(1996) 
高(图 2). 广元上寺剖面的有效烃源岩层位(图 2, 阴 影部分), 主要集中在栖霞组下段和上段的底部. 各 种生产力指标在有效烃源岩层内都具有较高的值, 其中生物碎屑含量和过剩铝具有较好的相关性, 说 明过剩铝比过剩钡能更好的指示缺氧环境的生产力 水平. 因为在缺氧环境中, 硫酸盐还原反应会消耗硫 酸钡中的硫酸根, 导致硫酸钡发生部分溶解, 从而造 成钡含量的降低, 致使估算的生产力水平偏低 (McManus 等, 1998; Griffith 和 Paytan, 2012).

\section{2 古氧相}

古氧相是地层(或沉积物)形成时沉积环境水体 中, 特别是底层水体中溶氧量特征及其变化的各种
沉积、生物和地球化学等特征的综合表现, 分为常氧 相、贫氧相、准厌氧相和厌氧相(颜佳新和张海清, 1996). 沉积有机碳主要受到水-沉积物界面氧化还原 条件的控制, 华南地区中二叠统栖霞组缺氧沉积特 征较为丰富, 包括岩石学、地球化学和古生态学的特 征(颜佳新，2004), 并且不同的指标往往表现出不同 的古氧相类型(颜佳新和刘新宇, 2007)。本文选取微 量元素比值 $(\mathrm{V} /(\mathrm{V}+\mathrm{Ni}))$ 和沉积构造作为古氧相的替代 指标(图 2). 前人对广元上寺剖面栖霞组的古氧相进 行过详细的研究(Ma 等, 2008b), 认为缺氧沉积主要 发生在栖霞组下段和上段的中部。其中，下段见 Zoophycos 遗迹化石, 并且发育大量海泡石页岩, 属 于轻度贫氧相; 上段发育大量纹层状灰岩，属于中度
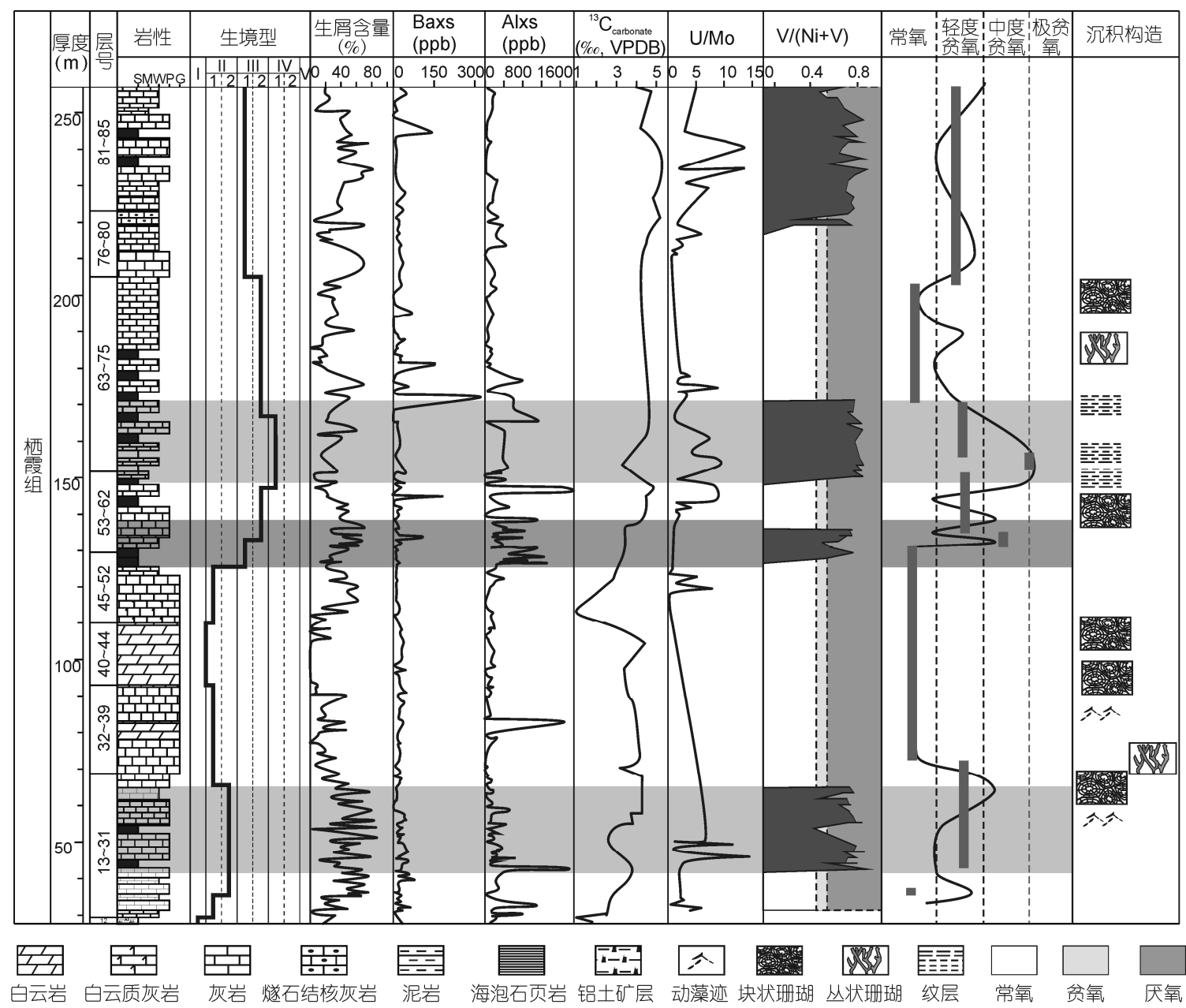

图 2 四川广元上寺剖面栖霞组地球生物相特征

浅灰色部分为烃源岩，暗灰色的部分为优质烃源岩，参考殷鸿福等(2011); 碳同位素据李朋威等(2010); 生产力指标据 Ma 等(2008a); 古氧相 指标据 $\mathrm{Ma}$ 等(2008b) 
贫氧相. 但是微量元素比值 $\mathrm{V} /(\mathrm{V}+\mathrm{Ni})$ 指标显示烃源 岩出现在厌氧环境, 说明该指标估算的氧化还原状 态往往比实际的要还原(Algeo 和 Maynard, 2004).

\section{3 埋藏有机碳}

埋藏有机碳代表最终有机质的聚集量, 其含量 受沉积至浅埋藏过程中, 在沉积颗粒、孔隙水及沉积 环境之间发生的一系列物理、化学及生物学作用的影 响(殷鸿福等, 2011). 在早期成岩阶段, 不同的微生 物功能群导致不同的地球生物学过程, 相继经历了 常氧氧化作用、硝酸盐还原作用、硫酸盐还原作用和 甲烷形成作用等阶段(谢树成等，2012). 不同的成岩 阶段, 元素的赋存状态会发生改变, 例如对现代大陆 边缘沉积物的研究表明, $\delta^{98} \mathrm{Mo}$ 与埋藏有机碳有一定 的相关性, 因此可以作为有机碳埋藏量的替代指标 (Algeo 和 Lyons, 2006). 上寺剖面栖霞组还没有详尽 的钼同位素数据报道, 最近的研究表明 $\delta^{98} \mathrm{Mo}$ 值与 $\mathrm{U} / \mathrm{Mo}$ 值具有相关性(周炼等, 2011), 因此可以用元素 比值 U/Mo 作为代替指标(殷鸿福等, 2011). 优质烃源 岩层的 U/Mo 值较低, 具有较高的埋藏效率, 特别是 在 50 59 层优质烃源岩部分(图 2).

\section{3 地球生物学过程}

\section{1 高生产力成因}

栖霞组作为中国南方四套区域海相烃源岩之一, 其具有较高的初级生产力已经是个共识, 但是对于 其高生产力的成因却有不同的解释. 吕炳全等(2010) 对南京栖霞山栖霞组的研究表明栖霞组烃源岩形成 于上升流发育的斜坡环境, 并且根据岩性的差异识 别出不同的上升流组合, 冷水动物群的出现也支持 这一解释. 下扬子地区巢湖栖霞组开展的沉积学、孢 粉相和有机地球化学综合研究表明栖霞组为二叠纪 海侵期形成的生物成因碳酸盐岩缺氧沉积, 有机质 来源于红藻、绿藻和蓝绿藻等各种低等藻类, 其类型 为腐泥型 (刘峰等, 2011). 对湖北恩施和湖南桑植地 区栖霞组微量元素的分析, 表明扬子台地栖霞早期 快速的海侵带来丰富的营养物质, 导致海洋表层初 级生产力提高(韦恒叶, 2013; Wei 等, 2012). 颜佳新 等(2002)通过对栖霞期海陆分布和古洋流格局的恢 复, 表明导致高生产力的营养元素是赤道流和赤道 逆流共同作用的结果, 并且这种格局一直持续到茅
口期. 上述对高生产力成因的解释都具有其合理性, 但是不能完全解释整个华南栖霞期的生产力特征. 大陆斜坡上升流虽然经常用来解释地质历史时期中 海相烃源岩的形成, 但是栖霞组碳酸盐岩沉积与典 型的上升流不同, 最主要的是缺乏磷沉积, 这与北美 磷矿组(Phosphoria Formation)沉积特征不一致(Piper, 2001; Piper 和 Link, 2002; Winguth 等, 2002).

中二叠世栖霞期, 与华南有关的中上扬子板块、 下扬子板块和华夏板块都处在赤道附近，属于热带 潮湿气候(图 3)。根据现实主义原理，本文在前人研 究的基础上恢复了栖霞期的古洋流格局(图 3(a)). 与 两半球信风带对应的分别是西向的南赤道暖流和北 赤道暖流. 这主要是由信风引起的风成流，是南北半 球环流的组成部分. 在南北赤道流中间是与赤道无 风带对应的赤道逆流. 北赤道暖流向西流动遇到扬 子板块和华北板块的阻挡，在科氏力的作用下，沿顺 时针方向运动, 最后在西风带的作用下, 向东运动, 完成环流; 其中一部分洋流在受阻后，沿无风带返回， 形成赤道逆流. 南赤道流向西运动的过程中遇到华 夏板块的阻挡，在科氏力的作用下，沿逆时针方向翻 转, 到达西风带后折回. 在古特提斯样内部也存在一 个顺时针方向的环流，受到松潘地块和扬子板块的 阻拦, 在信风带折回, 向西运动, 其中一支通过秦岭 海槽，与北赤道暖流汇合. 底层洋流由于受到大陆的 阻隔, 很难进入到研究区内, 只是华南板块最南边可 能会受到底层洋流的影响, 进入到黔桂裂陷槽. 除了 南北赤道流等表层洋流外, 还存一股次表层流沿赤道 自西向东流动(图 3(a); 蓝色箭头所示赤道潜流). 表 层洋流通常营养元素含量都很低, 而次表层洋流往往 含有较为丰富的营养元素, 例如现代太平洋赤道地区 的赤道潜流(Slemons 等, 2010). 中二叠世栖霞期赤道 潜流携带温跃层的海水(富含营养元素), 当海平面上 升时，赤道上升流将赤道潜流中的营养元素翻涌到表 层，促进低等藻类的繁盛，产生较高的初级生产力, 这种机制在现代东太平洋赤道上升流区已经得到了 证实(Radic 等, 2011). 古气候和古海洋模拟的结果同 样表明赤道地区在中二叠世发育广泛的上升流(图 3(b); Rees 等, 2002), 因此本文认为中二叠世栖霞期 的高生产力与赤道上升流有关, 营养元素经由赤道潜 流从古特提斯洋西岸输入. 赤道上升流在海侵的时候 更容易发生，所以栖霞组的烃源岩主要发育在海平面 上升时期，这已经得到了有机和无机碳同位素的证实 

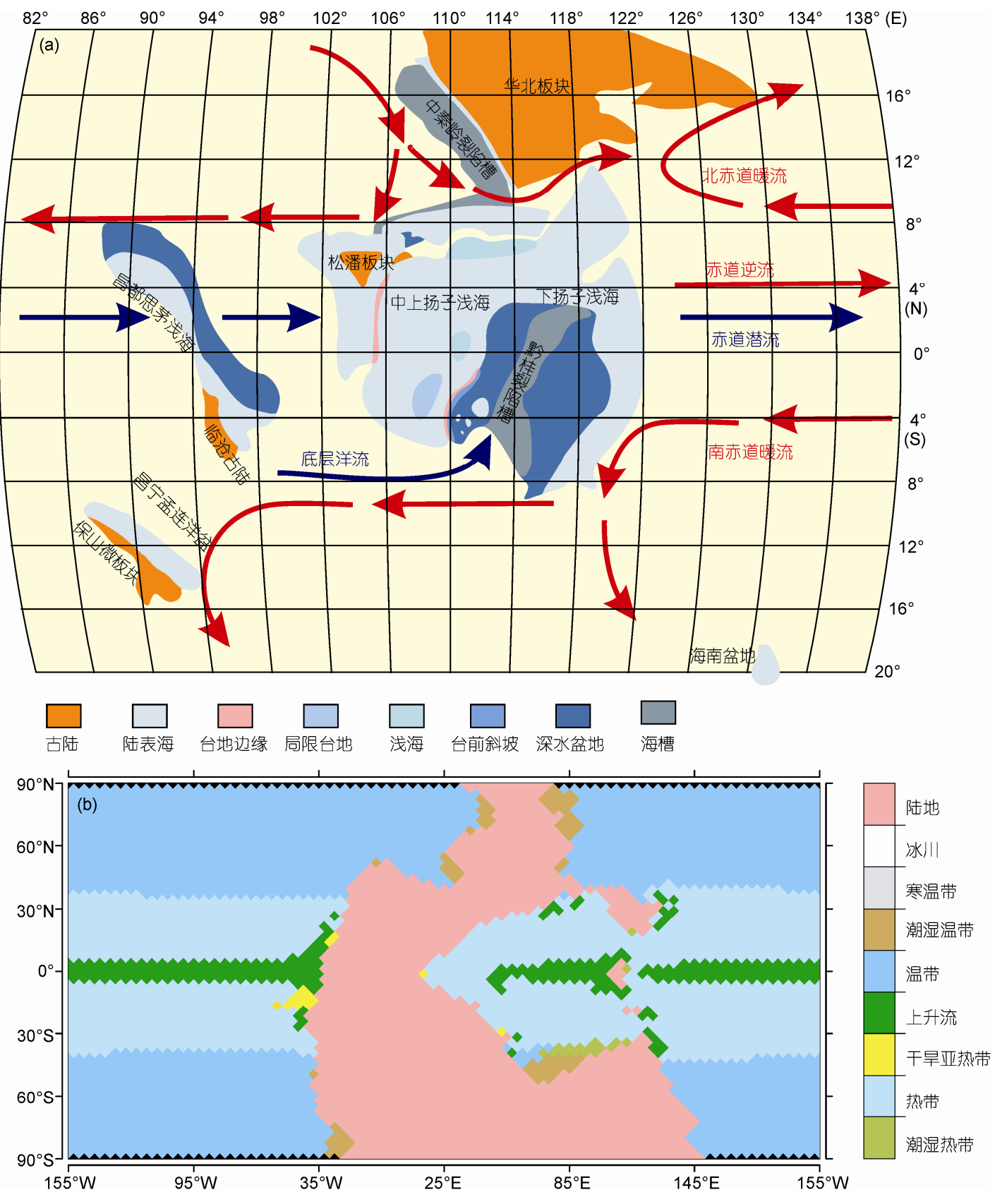

图 3 中二叠世古洋流格局恢复和古气候模拟结果

(a)中板块位置据殷鸿福未发表资料, 洋流类型修改自(颜佳新和刘新宇(2007); (b)根据 Winguth 等(2002)

(图 2). 层序地层学的研究也表明栖霞组烃源岩的发 育受到不同级次相对海平面变化的控制(Xie, 2008).

\section{2 缺氧环境的形成}

对于栖霞组缺氧环境的成因, 颜佳新等(2007)从地球 生物学的角度进行了解释, 认为较高的生产率可以
使得水体耗氧增加, 导致环境缺氧. 有机质在分解过 程中消耗水体中的可溶氧, 使得水体缺氧, 而进入到 硫酸盐还原阶段，因为没有足够的活性铁与产生的 硫化氢结合, 进一步加剧了缺氧状态, 进而有利于有 机质的保存(Capozzi 等, 2006; Kuypers 等, 2002; Lallier-Vergès 等, 1997; Pedersen 和 Calvert, 1990). 栖 
霞组纹层灰岩的有机质含量与生产力指数具有极高 的相关系数 $(r=0.94)$, 而与古氧相指数的相关系数非 常低 $(r=0.065)$, 也说明栖霞组的缺氧环境与较高的 生产力有直接的关系(陈慧等, 2010). 栖霞组的有效 烃源岩层与灰岩-泥灰岩韵律层的特征非常相似, 其 形成也与较高的生产力有关, 不同级别烃源岩的形 成与不同的成岩路径有关(图 4): 海平面较低的时候, 生产力水平较低, 有机质被有氧呼吸作用分解, 形成 以生物碎屑灰岩为主的碳酸盐岩, 形成不了烃源岩; 随着海平面上升, 有机质氧化过程可以达到铁锰还 原带, 促进碳酸盐沉积物的胶结而形成灰岩为主的 韵律层, 为较差的烃源岩; 当海平面继续上升, 赤道 上升流开始发育, 生产力大幅度提高, 有机质输入增 加而大量消耗水体中的可溶氧, 使得有机质进入硫 酸盐还原阶段, 产生硫化氢, 不稳定的碳酸盐矿物被 溶蚀(Schulte 和 Bard, 2003), 经过机械和化学压实作 用, 形成纹层状灰岩, 为优质烃源岩; 随后海平面下 降, 生产力降低, 形成差烃源岩.

\section{3 烃源岩的形成条件}

海相烃源岩形成的主要因素包括海洋表层初级 生产力和保存条件, 但是对于两者的相对重要性一
直存有争议(Caplan 和 Marc Bustin, 2001; KodransNsiah 等, 2009; Schulte 等, 1999). 生产力观点认为有 机质富集的主要原因是高生产力, 与氧化还原条件 无关, 主要的例子就是现代的上升流区; 而持保存条 件观点的学者则认为在厌氧环境中, 即便没有较高 的生产力也能富集有机质, 特别是在硫化环境中, 黑 海就是现代的实例, 另外对白严纪的大洋缺氧事件 的解释也经常采用这一机制. 具体到栖霞组烃源岩 的形成, 生产力和保存条件都非常重要, 较高的生产 力形成物质基础, 而适合的保存环境则有利于有机 质的保存(Xie 等, 2008). 烃源岩的形成要经历有机质 的生产、沉积和埋藏三个环节, 每个环节都影响有机 质的最终保存. 栖霞组烃源岩主要形成于下部浅海 生境型(图 2), 其深度相当于浅海陆棚环境, 处在风 暴浪基面以下, 具有较高的生产力和安静的沉积环 境, 有利于有机质的保存. 而海侵和上升流的发生加 剧了环境的缺氧状态, 更加有利于有机质的保存.

\section{4 结论}

(1) 栖霞组烃源岩的形成与海平面上升产生的 赤道上升流有关. 维持高生产力的营养元素来自沿

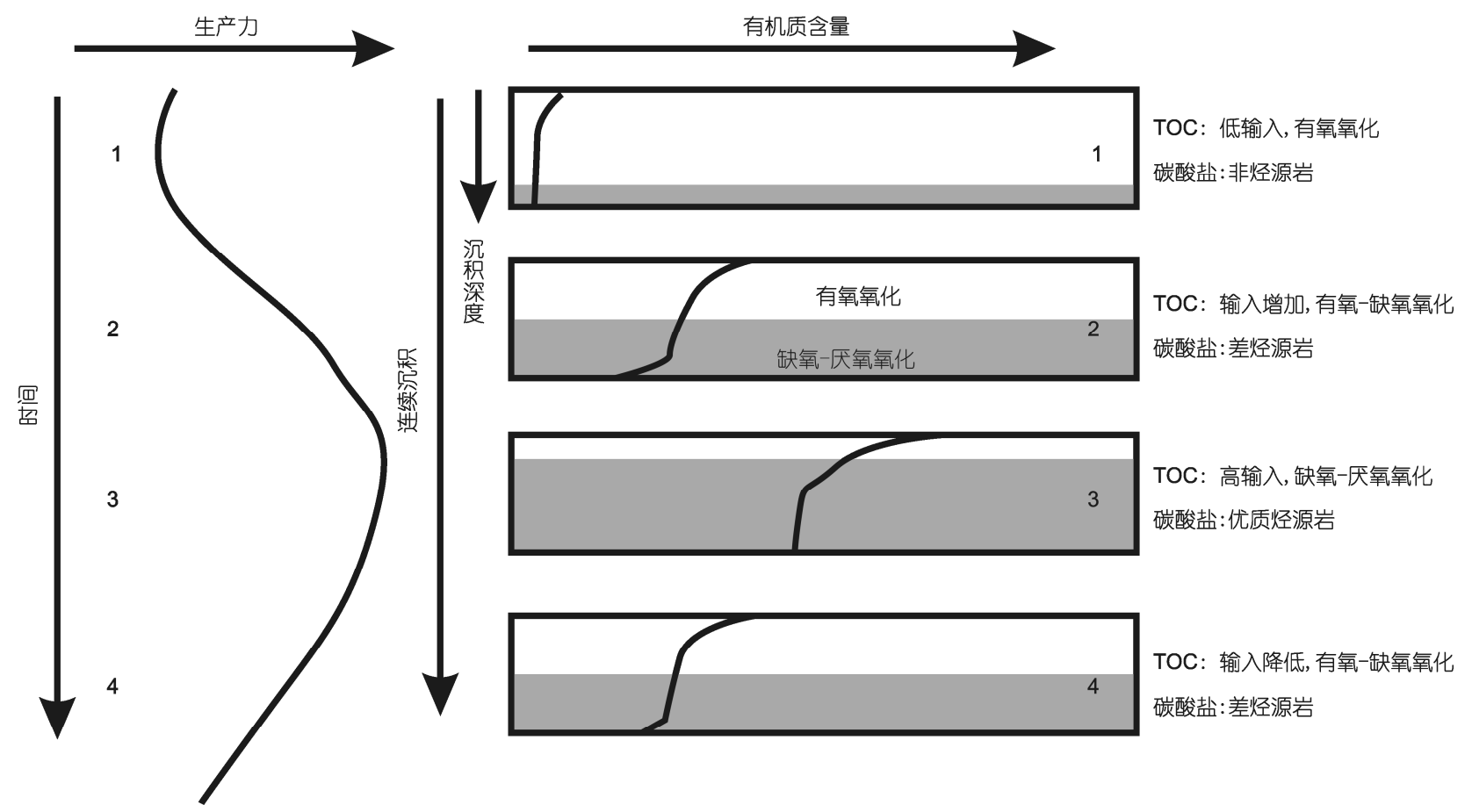

图 4 栖霞组烃源岩形成的地球生物过程 
着赤道自西向东的赤道潜流.

(2) 高生产力产生的有机质在分解过程中消耗 了水体中的可溶氧, 在较深水的下部浅海生境型中 形成了缺氧环境, 有利于有机质的保存, 成为发育优
质海相烃源岩的物质基础.

(3) 结合当时的古海洋和古气候条件, 利用地球 生物学对海相烃源岩进行正演评价, 是对传统烃源 岩评价的良好补充, 具有很好的应用前景.

致谢中国科学院地质与地球物理研究所陈代钊研究员提供了部分参考文献, 评审专家提出了宝贵的修改建议, 在 此表示感谢.

\section{参考文献}

曹婷婷, 徐思煌, 王约, 等. 2011. 四川盆地南江杨坝地区下寒武统烃源岩形成的地球生物学条件. 石油与天然气地质, 32: 11-16 陈慧, 解习农, 李红敬, 等. 2010. 利用古氧相和古生产力替代指标评价四川上寺剖面二叠系海相烃源岩. 古地理学报, 12: 324-333 陈建平, 梁狄刚, 张水昌, 等. 2012. 中国古生界海相烃源岩生烃潜力评价标准与方法. 地质学报, 86: 1132-1142 冯增昭, 杨玉卿. 1996. 中国南方二叠纪岩相古地理. 沉积学报, 14: 1-11

胡超涌, 潘涵香, 马仲武, 等. 2007. 海相碳酸盐岩中的铁: 烃源岩古生产力评估的新指标. 地球科学一中国地质大学学报, 32: 755-758 贾建忠, 万晓樵, 张翼翼, 等. 2009. 白严纪中期海相富有机碳沉积的地球生物学背景. 地学前缘, 16: 143-152

李波, 颜佳新, 薛武强, 等. 2012. 四川广元地区中二叠世斑状白云岩成因及地质意义. 地球科学一中国地质大学学报, 37: 136-146

李朋威, 吴夏, 白晓, 等. 2010. 四川广元上寺剖面二叠系栖霞组沉积碳库与有机碳埋藏. 古地理学报, 12: 301-306

刘峰, 蔡进功, 吕炳全, 等. 2011. 巢湖地区栖霞组碳酸盐烃源岩的形成及影响因素. 中国科学: 地球科学, 41: 873-886

刘喜停, 颜佳新, 薛武强. 2012. 灰岩-泥灰岩韵律层的差异成岩作用. 地质论评, 58: 627-635

吕炳全, 蔡进功, 刘峰, 等. 2010. 栖霞组中台缘斜坡上升流沉积相及其与烃源岩的关系. 海洋地质与第四纪地质, 30: 109-118

马志金, 李波, 颜佳新, 等. 2011. 四川广元中二叠统栖霞组似球粒灰岩微相特征及沉积学意义. 沉积学报, 29: 449-457

郄文昆, 张雄华, 蔡雄飞, 等. 2007. 华南地区石炭纪-早二叠世早期成冰期的地球生物学过程与烃源岩的形成. 地球科学—中国地质大 学学报, 32: 803-810

腾格尔, 刘文汇, 徐永昌, 等. 2006. 高演化海相碳酸盐烃源岩地球化学综合判识——鄂尔多斯盆地为例. 中国科学 D辑: 地球科学, 36: $167-176$

韦恒叶, 陈代钊, 遇吴, 等. 2011. 鄂西地区中二叠统栖霞组下部烃源岩形成机理. 地质科学, 46: 68-82

韦恒叶, 汪建国, 遇吴, 等. 2013. 海平面变化在湖南西部桑植地区栖霞组富有机碳沉积物形成中的作用. 地球科学一中国地质大学学 报, 38: 266-276

谢树成, 杨欢, 罗根明, 等. 2012. 地质微生物功能群: 生命与环境相互作用的重要突破口. 科学通报, 57: 3-22

谢树成, 殷鸿福, 解习农, 等. 2007. 地球生物学方法与海相优质烃源岩形成过程的正演和评价. 地球科学一中国地质大学学报, 32 : $727-740$

颜佳新, 刘新宇. 2007. 从地球生物学角度讨论华南中二叠世海相烃源岩缺氧沉积环境成因模式. 地球科学一中国地质大学学报, 32: 789-796

颜佳新, 张海清. 1996. 古氧相———新的沉积学研究领域. 地质科技情报, 15: 7-13

颜佳新, 赵坤. 2002. 二叠-三叠纪东特提斯地区古地理、古气候和古海洋演化与地球表层多圈层事件耦合. 中国科学 D辑: 地球科学, 32: $751-759$

颜佳新. 2004. 华南地区二叠纪栖霞组碳酸盐岩成因研究及其地质意义. 沉积学报, 22: 579-587

殷鸿福, 谢树成, 秦建中, 等. 2008. 对地球生物学, 生物地质学和地球生物相的一些探讨. 中国科学 D 辑: 地球科学, 38: 1473-1480

殷鸿福, 谢树成, 颜佳新, 等. 2011. 海相碳酸盐烃源岩评价的地球生物学方法. 中国科学: 地球科学, 41: 895-909

周炼, 苏洁, 黄俊华, 等. 2011. 判识缺氧事件的地球化学新标志—钿同位素. 中国科学: 地球科学, 41: 309-319

Algeo T J, Lyons T W. 2006. Mo-total organic carbon covariation in modern anoxic marine environments: Implications for analysis of paleoredox and paleohydrographic conditions. Paleoceanography, 21, doi 10.1029/2004pa001112

Algeo T J, Maynard J B. 2004. Trace-element behavior and redox facies in core shales of Upper Pennsylvanian Kansas-type cyclothems. Chem Geol, 206: 289-318

Caplan M L, Marc Bustin R. 2001. Palaeoenvironmental and palaeoceanographic controls on black, laminated mudrock deposition: Example from Devonian-Carboniferous strata, Alberta, Canada. Sediment Geol, 145: 45-72

Capozzi R, Dinelli E, Negri A, et al. 2006. Productivity-generated annual laminae in Mid-Pliocene sapropels deposited during precessionally 
forced periods of warmer Mediterranean climate. Paleogeogr Paleoclimatol Paleoecol, 235: 208-222

Dymond J, Suess E, Lyle M. 1992. Barium in deep-sea sediment: A geochemical proxy for paleoproductivity. Paleoceanography, 7: 163-181

Franois R, Altabet M A, Yu E-F, et al. 1997. Contribution of Southern Ocean surface-water stratification to low atmospheric $\mathrm{CO}_{2}$ concentrations during the last glacial period. Nature, 389: 929-935

Griffith E M, Paytan A. 2012. Barite in the ocean-occurrence, geochemistry and palaeoceanographic applications. Sedimentology, 59: 1817-1835

Kodrans-Nsiah M, März C, Harding I C, et al. 2009. Are the Kimmeridge Clay deposits affected by "burn-down" events? Palynological and geochemical studies on a 1 metre long section from the Upper Kimmeridge Clay Formation (Dorset, UK). Sediment Geol, 222: 301-313

Kuypers M M M, Pancost R D, Nijenhuis I A, et al. 2002. Enhanced productivity led to increased organic carbon burial in the euxinic North Atlantic basin during the late Cenomanian oceanic anoxic event. Paleoceanography, 17, doi 10.1029/2000pa000569

Lallier-Vergès E, Hayes J M, Boussafir M, et al. 1997. Productivity-induced sulphur enrichment of hydrocarbon-rich sediments from the Kimmeridge Clay Formation. Chem Geol, 134: 277-288

Ma Z W, Hu C Y, Yan J X, et al. 2008a. Biogeochemical records at Shangsi section, northeast Sichuan in China: The Permian paleoproductivity proxies. J Earth Sci, 19: 461-470

Ma Z X, Yan J X, Xie X N, et al. 2008b. Depositional and ecological features of Permian oxygen deficient deposits at Shangsi section, northeast Sichuan, China. J Earth Sci, 19: 488-495

McManus J, Berelson W M, Klinkhammer G P, et al. 1998. Geochemistry of barium in marine sediments: Implications for its use as a paleoproxy. Geochim Cosmochim Acta, 62: 3453-3473

Murray R, Leinen M. 1996. Scavenged excess aluminum and its relationship to bulk titanium in biogenic sediment from the central equatorial Pacific Ocean. Geochim Cosmochim Acta, 60: 3869-3878

Pedersen T F, Calvert S E. 1990. Anoxia vs productivity: What controls the formation of organic-carbon-rich sediments and sedimentary rocks? AAPG Bull, 74: 454-466

Piper D Z, Link P K. 2002. An upwelling model for the Phosphoria sea: A Permian, ocean-margin sea in the northwest United States. AAPG Bull, 86: $1217-1235$

Piper D Z. 2001. Marine chemistry of the Permian Phosphoria Formation and basin, southeast Idaho. Econ Geol, 96: 599-620

Radic A, Lacan F, Murray J W. 2011. Iron isotopes in the seawater of the equatorial Pacific Ocean: New constraints for the oceanic iron cycle. Earth Planet Sci Lett, 306: 1-10

Rees P M A, Ziegler A M, Gibbs M T, et al. 2002. Permian phytogeographic patterns and climate data/model comparisons. J Geol, 110: 1-31

Schulte S, Bard E. 2003. Past changes in biologically mediated dissolution of calcite above the chemical lysocline recorded in Indian Ocean sediments. Quat Sci Rev, 22: 1757-1770

Schulte S, Rostek F, Bard E, et al. 1999. Variations of oxygen-minimum and primary productivity recorded in sediments of the Arabian Sea. Earth Planet Sci Lett, 173: 205-221

Slemons L O, Murray J W, Resing J, et al. 2010. Western Pacific coastal sources of iron, manganese, and aluminum to the Equatorial Undercurrent. Glob Biogeochem Cycle, 24, doi 10.1029/2009gb003693

Wei H Y, Chen D Z, Wang J G, et al. 2012. Organic accumulation in the lower Chihsia Formation(Middle Permian)of South China: Constraints from pyrite morphology and multiple geochemical proxies. Paleogeogr Paleoclimatol Paleoecol, 353-355: 73-86

Winguth A M E, Heinze C, Kutzbach J E, et al. 2002. Simulated warm polar currents during the middle Permian. Paleoceanography, 17, doi 10.1029/2001pa000646

Xie X N, Li H J, Xiong X, et al. 2008. Main controlling factors of organic matter richness in a Permian section of Guangyuan, northeast Sichuan. J Earth Sci, 19: 507-517 